\title{
Fuzzy Soft Mathematical Morphology
}

\author{
A. Gasteratos, I. Andreadis and Ph. Tsalides
}

\author{
Laboratory of Electronics \\ Section of Electronics and Information Systems Technology \\ Department of Electrical and Computer Engineering \\ Democritus University of Thrace \\ GR-671 00 Xanthi, Greece \\ E-mail : ioannis@orfeas.ee.duth.gr
}

Abstract : A new framework which extends the concepts of soft mathematical morphology into fuzzy sets is presented in this paper. Images can be considered as arrays of fuzzy singletons on the Cartesian grid. Based on this notion the definitions for the basic fuzzy soft morphological operations are derived. Compatibility with binary soft mathematical morphology as well as the algebraic properties of fuzzy soft operations are studied. Explanation of the defined operations is also provided through several examples and experimental results.

Indexing terms : computer vision, mathematical morphology, fuzzy sets. 


\section{Introduction}

Mathematical morphology was firstly introduced by Matheron [1] and Serra $[2,3]$ as a methodology for image processing. In this early form, mathematical morphology handles binary images as sets and probes them with a structuring element. The latter is a set, normally smaller than the image on which it is translated. By translating the structuring element over an image, and by applying basic set operations, such as intersection or union, the basic morphological operations are obtained. Grey-scale mathematical morphology is a natural extension of binary mathematical morphology into grey-scale images. The operations of intersection and union used in binary mathematical morphology are replaced by minimum and maximum operations, respectively. A review of grey-scale mathematical morphology, with particular emphasis on algorithms and applications is presented in [4]. The two basic morphological operations are erosion and dilation, from which all the other morphological transforms can be composed. Morphological transforms can decompose complex shapes into more meaningful representations and separate them from undesirable parts [5]. Mathematical morphology has provided solutions to many computer vision problems, such as noise suppression, feature extraction, edge detection etc. [6].

Sinha and Dougherty [7] have introduced fuzzy mathematical morphology. In this approach the images are not treated as crisp binary sets, but as fuzzy sets. The set union and intersection have been replaced by fuzzy bold union and bold intersection, respectively, in order to formulate fuzzy erosion and dilation, respectively. This attempt to adapt mathematical morphology into fuzzy set theory is not unique. Several other attempts have been developed independently by researchers, and they are all described/discussed in [8]. 
Another approach to mathematical morphology is soft mathematical morphology introduced by Koskinen et al. [9]. In this approach weighted order statistics are used instead of the minima or maxima. The weights depend on the structuring element, which is divided into two parts : the core, the pixels that participate with weights greater than one, and the soft boundary, the pixels that participate with weights equal to one. It has been shown that soft morphological operations are less sensitive to additive noise and to small variations in object shape [10-12].

In this paper a new framework which extends the concepts of soft mathematical morphology into fuzzy sets is presented. The definitions of the basic fuzzy soft morphological operations are given and their properties are also studied. It is shown that fuzzy soft morphological operations are dual, translation invariant and increasing, whilst they do not distribute over basic set operations, such as intersection and union. Furthermore, it is shown that fuzzy soft opening and closing are neither idempotent nor anti-extensive and extensive, respectively. The paper is organised as follows. In section 2 fuzzy sets are reviewed. Binary and grey-scale mathematical morphology are summarised in section 3 . In section 4 binary and grey-scale soft mathematical morphology are presented. Fuzzy mathematical morphology is reviewed in section 5. In section 6 the new definitions of fuzzy soft mathematical morphology are presented and their algebraic properties are studied. Examples and experimental results illustrating the new definitions are presented in section 7 . Concluding remarks are made in section 8 .

\section{Fuzzy Sets Fundamentals}

Membership, in the $\mathrm{N}$-dimensional Euclidean space $\mathrm{E}^{\mathrm{N}}$, of a crisp set $\mathrm{A}$, may be defined in terms of the characteristic function $\mu_{\mathrm{A}}: \mathrm{E}^{\mathrm{N}} \rightarrow\{0,1\}[13]$ : 
$\mu_{\mathrm{A}}(x)= \begin{cases}1 & \text { if } x \in \mathrm{A} \\ 0 & \text { if } x \notin \mathrm{A}\end{cases}$

Likewise, membership of a fuzzy set A is characterised by its membership function $\mu_{\mathrm{A}}: \mathrm{E}^{\mathrm{N}} \rightarrow[0,1]$. The value $\mu_{\mathrm{A}}(x)$ of the membership function at point $x$ of the $\mathrm{N}$-dimensional Euclidean space denotes the degree that point $x$ belongs to set $\mathrm{A}$.

The basic set operations, i.e. intersection, union, complement and difference, in terms of the characteristic functions (for crisp sets), or the membership functions (for fuzzy sets), are defined as follows:

$\mu_{\mathrm{A} \cap \mathrm{B}}(x)=\min \left[\mu_{\mathrm{A}}(x), \mu_{\mathrm{B}}(x)\right]$

$\mu_{\mathrm{A} \cup \mathrm{B}}(x)=\max \left[\mu_{\mathrm{A}}(x), \mu_{\mathrm{B}}(x)\right]$

$\mu_{\mathrm{A}^{\mathrm{c}}}(x)=1-\mu_{\mathrm{A}}(x)$

$\mu_{\mathrm{A} \backslash \mathrm{B}}(x)=\min \left[\mu_{\mathrm{A}}(x), 1-\mu_{\mathrm{B}}(x)\right]$

Finally, the subset relation is :

$\mathrm{A} \subseteq \mathrm{B} \Leftrightarrow \mu_{\mathrm{A}}(x)=\min \left[\mu_{\mathrm{A}}, \mu_{\mathrm{B}}\right] \Leftrightarrow \mu_{\mathrm{B}}(x)=\max \left[\mu_{\mathrm{A}}, \mu_{\mathrm{B}}\right]$

Let $Z^{2}$ be the Cartesian grid and $G=\{0,1 / L, 2 / L, \ldots L / L\}$ the set of $L+1$ normalised grey-levels. A normalised image $\mathrm{A}$ is defined as a mapping A: $Z^{2} \rightarrow G$. Bearing the above definition in mind, an image can be considered as an array of fuzzy singletons, each with a membership function equal to the normalised grey-level value of the image at that point [14, 15]. A fuzzy singleton is a fuzzy set whose support is a single point. 


\section{Standard Morphology [5, 6]}

In this paper binary and grey-scale mathematical morphology are referred to as standard mathematical morphology. This distinction is made frequently in the literature, in order to be discriminated by their extensions, such as soft mathematical morphology and fuzzy mathematical morphology.

\subsection{Binary morphology}

Binary erosion and dilation are defined according to eqn.(7) and eqn.(8), respectively :

$\mathrm{A}$ È $?=\bigcap_{x \in \mathrm{B}}(\mathrm{A})_{-x}$

$$
\mathrm{A} \oplus ?=\bigcup_{x \in \mathrm{B}}(\mathrm{A})_{x}
$$

where $\mathrm{A}, \mathrm{B}$ are sets of $\mathrm{Z}^{2} ;(\mathrm{A})_{x}$ is the translation of $\mathrm{A}$ by $x$, and $-\mathrm{B}$ is the reflection of $\mathrm{B}$. These are defined as follows :

$$
\begin{aligned}
& (\mathrm{A})_{x}=\left\{c \in \mathrm{Z}^{2} \mid c=a+x \text { for some } a \in \mathrm{A}\right\} \\
& -\mathrm{B}=\{x \mid \text { for some } b \in \mathrm{B}, x=-b\}
\end{aligned}
$$

Set $\mathrm{A}$ is the image under process and set $\mathrm{B}$ is the structuring element.

The definitions of binary opening and closing are :

$\mathrm{A} \circ \mathrm{B}=(\mathrm{AE} \mathrm{B}) \oplus \mathrm{B}$ and

$\mathrm{A} \bullet \mathrm{B}=(\mathrm{A} \oplus \mathrm{B}) \mathrm{E} \mathrm{B}$

respectively. 


\subsection{Grey-scale morphology}

In terms of grey-scale morphology erosion and dilation are :

$$
\begin{aligned}
& (f \grave{\mathrm{E}} g)(x)=\min _{y \in \mathrm{G}}\{f(x+y)-g(y)\} \text { and } \\
& (f \oplus g)(x)=\max _{\substack{y \in \mathrm{G} \\
(x-y) \in \mathrm{F}}}\{f(x-y)+g(y)\}
\end{aligned}
$$

respectively.

where $x, y \in \mathrm{Z}^{2}$ are the spatial coordinates,

$f: \mathrm{F} \rightarrow \mathrm{Z}$ is the integer value grey-scale image,

$g: \mathrm{G} \rightarrow \mathrm{Z}$ is the grey-scale structuring element and

$\mathrm{F}, \mathrm{G} \subseteq \mathrm{Z}^{2}$, are the domains of the grey-scale image and grey-scale structuring element, respectively.

\section{Soft Mathematical Morphology [9, 10]}

In soft morphological operations the maximum or the minimum operations, used in standard morphology, are replaced by weighted order statistics. Furthermore, the structuring element B is divided into two subsets: the core $\mathrm{B}_{1}$ and the soft boundary $\mathrm{B}_{2}=\mathrm{B} \backslash \mathrm{B}_{1}$.

\subsection{Grey-scale soft mathematical morphology}

In soft morphological erosion and in soft morphological dilation of an image $f$ the pixels of $f$ are combined with the pixels of the structuring element as in traditional morphology; the results which are related with the soft boundary of the structuring element and the results which are related with the core of the structuring element (repeated $k$ times) are put in an ascending or a descending order list. The $k$ th element of this list is the result of soft morphological erosion or dilation. Let $\{k \diamond f(x)\}$ denote the repetition of $f(x)$ 
for $k$ times, i.e. $\{k \diamond f(x)\}=\{f(x), f(x), \ldots f(x)\}$ (k times). Soft morphological erosion of a grey-scale image $f$ by a soft grey-scale structuring element $[\beta, a, k]$ is $[11]$ :

$$
f \grave{\mathrm{E}}[\beta, a, k](x)=k \text { th } \operatorname{smallest~}_{\substack{(x+y) \in \mathrm{K}_{1} \\(x+z) \in \mathrm{K}_{2}}} \text { of }(\{k \diamond(f(y)-a(x+y))\} \cup\{f(z)-\beta(x+z)\})
$$

Soft morphological dilation of $f$ by $[\beta, a, k]$ is :

$$
f \oplus[\beta, a, k](x)=k \text { th } \underset{\substack{(x-y) \in \mathrm{K}_{1} \\(x-z) \in \mathrm{K}_{2}}}{\arg \operatorname{est}} \operatorname{of}(\{k \diamond(f(y)+a(x-y))\} \cup\{f(z)+\beta(x-z)\})
$$

where $x, y, z \in \mathrm{Z}^{2}$, are the spatial coordinates,

$f: \mathrm{F} \rightarrow \mathrm{Z}$ is the grey-scale image,

$a: \mathrm{K}_{1} \rightarrow \mathrm{Z}$ is the core of the grey-scale structuring element,

$\beta: \mathrm{K}_{2} \rightarrow \mathrm{Z}$ is the soft boundary of the grey-scale structuring element,

$\mathrm{F}, \mathrm{K}_{1}, \mathrm{~K}_{2} \subseteq \mathrm{Z}^{2}$ are the domains of the grey-scale image, the core of the grey-scale structuring element and the soft boundary of the grey-scale structuring element, respectively, and

$\mathrm{K}_{2}=\mathrm{K} \backslash \mathrm{K}_{1}$, where $\mathrm{K} \subseteq \mathrm{Z}^{2}$ is the domain of the grey-scale structuring element.

\subsection{Binary soft mathematical morphology}

The basic definitions of the binary soft erosion and dilation, are respectively [12] :

$$
\left(\mathrm{AÈ}\left[?_{1}, ?_{2}, k\right]\right)(x)=\left\{\begin{array}{cc}
1 & \text { if }\left(k \times \mathrm{Card}\left[\mathrm{A} \cap\left(\mathrm{B}_{1}\right)_{x}\right]+\mathrm{Card}\left[\mathrm{A} \cap\left(\mathrm{B}_{2}\right)_{x}\right]\right) \geq \\
& \geq k \mathrm{Card}\left[\mathrm{B}_{1}\right]+\mathrm{Card}\left[\mathrm{B}_{2}\right]-k+1 \\
0 & \text { otherwise }
\end{array}\right.
$$


$\left(\mathrm{A} \oplus\left[?_{1}, ?_{2}, k\right]\right)(x)= \begin{cases}1 & \text { if }\left(k \times \mathrm{Card}\left[\mathrm{A} \cap\left(\mathrm{B}_{1}\right)_{x}\right]+\mathrm{Card}\left[\mathrm{A} \cap\left(\mathrm{B}_{2}\right)_{x}\right]\right) \geq k \\ 0 & \text { otherwise }\end{cases}$

where, $\operatorname{Card}[\mathrm{X}]$ denotes the cardinality of set X.

\section{Fuzzy Mathematical Morphology}

In the past several attempts have been made to apply fuzzy set theory to mathematical morphology. These attempts have resulted in different approaches and definitions. These are reviewed in [8], where a general framework is proposed. This framework leads to an infinity of fuzzy mathematical morphologies, which are constructed in families with specific properties. In this paper the approach described by Sinha and Dougherty [7] has been used. This is a special case of the framework presented in [8]. In this approach, fuzzy mathematical morphology is examined in terms of fuzzy fitting. The fuzziness is introduced by the degree to which the structuring element fits into the image. The operations of erosion and dilation of a fuzzy image by a fuzzy structuring element having a bounded support, are defined in terms of their membership functions as follows :

$$
\begin{aligned}
\mu_{\mathrm{A} \grave{\mathrm{B}}}(x) & =\min _{y \in \mathrm{B}}\left[\min \left[1,1+\mu_{\mathrm{A}}(x+y)-\mu_{\mathrm{B}}(y)\right]\right] \\
& =\min _{1}\left[1, \min _{y \in \mathrm{B}}\left[1+\mu_{\mathrm{A}}(x+y)-\mu_{\mathrm{B}}(y)\right]\right] \text { and } \\
\mu_{\mathrm{A} \oplus \mathrm{B}}(x) & =\max _{y \in \mathrm{B}}\left[\max \left[0, \mu_{\mathrm{A}}(x-y)+\mu_{\mathrm{B}}(y)-1\right]\right]= \\
& =\max _{0}\left[0, \max _{y \in \mathrm{B}}\left[\mu_{\mathrm{A}}(x-y)+\mu_{\mathrm{B}}(y)-1\right]\right]
\end{aligned}
$$

where $x, y \in \mathrm{Z}^{2}$ are the spatial coordinates and 
$\mu_{\mathrm{A}}, \mu_{\mathrm{B}}$ are the membership functions of the image and the structuring element, respectively.

It is obvious from eqns. (19) and (20) that the result of both fuzzy erosion and dilation have membership functions whose values are restricted to the interval $[0,1]$.

\section{Fuzzy Soft Mathematical Morphology}

\subsection{Definitions}

Fuzzy soft mathematical morphology operations are defined taking into consideration that in soft mathematical morphology the structuring element is divided into two subsets, i.e. the core and the soft boundary, from which the core 'weights' more than the soft boundary in the formation of the final result. Also, depending on $k$, the $k$ th order statistic provides the result of the operation. Also, fuzzy soft morphological operation should preserve the notion of fuzzy fitting [7]. Thus, the definitions for fuzzy soft erosion and fuzzy soft dilation are derived in this paper for the first time as far as we know, as follows :

$$
\begin{gathered}
\mu_{\mathrm{A} \dot{\mathrm{E}}\left[\mathrm{B}_{1}, \mathrm{~B}_{2}, k\right]}(x) \equiv \min [1, k \text { th smallest of } \\
\substack{y \in \mathrm{B}_{1} \\
z \in \mathrm{B}_{2}} \\
\left\{k \diamond\left(\mu_{\mathrm{A}}(x+y)-\mu_{\mathrm{B}_{1}}(y)+1\right)\right\} \cup \\
\left.\left.\left\{\mu_{\mathrm{A}}(x+z)-\mu_{\mathrm{B}_{2}}(z)+1\right\}\right)\right]
\end{gathered}
$$

and

$$
\begin{gathered}
\mu_{\mathrm{A} \oplus\left[\mathrm{B}_{1}, \mathrm{~B}_{2}, k\right]}(x) \equiv \max \left[0 , k \text { th } \underset { \substack { y \in \mathrm { B } _ { 1 } \\
z \in \mathrm { B } _ { 2 } } } { \operatorname { a r g } \operatorname { e s t } \operatorname { o f } } \left(\left\{k \diamond\left(\mu_{\mathrm{A}}(x-y)+\mu_{\mathrm{B}_{1}}(y)-1\right)\right\} \cup\right.\right. \\
\left.\left.\left\{\mu_{\mathrm{A}}(x-z)+\mu_{\mathrm{B}_{2}}(z)-1\right\}\right)\right]
\end{gathered}
$$

where $x, y, z \in \mathrm{Z}^{2}$, are the spatial coordinates and

$\mu_{\mathrm{A}}, \mu_{\mathrm{B} 1}, \mu_{\mathrm{B} 2}$ are the membership functions of the image, the core of the structuring element and the soft boundary of the structuring element. 
Additionally, for the fuzzy structuring element $\mathrm{B} \subset \mathrm{Z}^{2}: \mathrm{B}=\mathrm{B}_{1} \cup \mathrm{B}_{2}$ and $\mathrm{B}_{1} \cap \mathrm{B}_{2}=\varnothing$.

It is obvious that for $k=1$ eqns. (21) and (22) are reformed to eqns. (19) and (20) respectively, i.e. simple fuzzy morphology.

Example $1:$ In this example the adopted coordinate system is (row, column). The arrows denote the origin of the coordinate system and direction. Let us consider the image $\mathrm{A}$ and the structuring element $\mathrm{B}$. The core in $\mathrm{B}$ is separated from the soft boundary by a bold line. Fuzzy soft erosion and fuzzy soft dilation are computed for cases $k=1$ and $k=2$.

If $k>\operatorname{Card}\left[\mathrm{B}_{2}\right]$, where $\mathrm{B}_{2}$ is the soft boundary of the structuring element, the soft morphological operations are affected only by the core $\mathrm{B}_{1}$, i.e. using $\mathrm{B}_{1}$ as the structuring element. Therefore, in this case the nature of soft morphological operations is not preserved $[10,11]$. For this reason the constraint $k \leq \min \left\{\operatorname{Card}(\mathrm{B}) / 2, \operatorname{Card}\left(\mathrm{B}_{2}\right)\right\} \quad$ is adopted in fuzzy soft mathematical morphology, as well as in soft mathematical morphology. In this example only the cases of $k=1$ and $k=2$ are considered, in order to comply with this constraint.

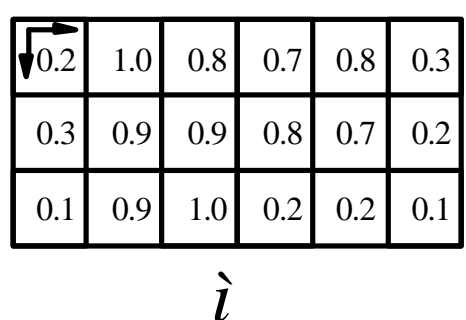

A

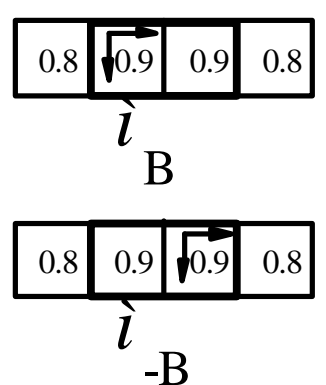

$-\mathrm{B}$

Case $1: k=1$

The fuzzy soft erosion of the image is calculated as follows : 


$$
\begin{aligned}
& \mu_{?}(0,0)=\mu_{\mathrm{AE}}\left[\mathrm{B}_{1}, \mathrm{~B}_{2}, 1\right] \\
& \mu_{?}(0,1)=\min [1, \min [0.2-0.8+1,1-0.9+1,0.8-0.9+1,0.7-0.8+1]]=0.4 \\
& \cdot \\
& \mu_{?}(5,2)=\min [1, \min [0.2-0.8+1,0.1-0.9+1]]=0.2
\end{aligned}
$$

Therefore, the eroded image is :

\begin{tabular}{|c|c|c|c|c|c|}
\hline$\sqrt{0.3}$ & 0.4 & 0.8 & 0.5 & 0.4 & 0.4 \\
\hline 0.4 & 0.5 & 0.9 & 0.4 & 0.3 & 0.3 \\
\hline 0.2 & 0.3 & 0.3 & 0.3 & 0.2 & 0.2 \\
\hline
\end{tabular}

The values of the eroded image at points $(0,2)$ and $(1,2)$ are higher than the rest values of the image. This agrees with the notion of fuzzy fitting, since only at these points the structuring element fits better than the rest points of the image. Fuzzy erosion quantifies the degree of structuring element fitting. The larger the number of pixels of the structuring element, the more difficult the fitting. Furthermore, fuzzy soft erosion shrinks the image. If fuzzy image A is considered as a noisy version of a binary image [7], then the object of interest consists of points $(0,1),(0,2),(0,3),(0,4),(1,1),(1,2),(1,3),(1$, $4),(2,1),(2,2)$ and $(2,3)$ and the rest is the background. By eroding the image with a 4-pixel horizontal structuring element it would be expected that the eroded image would comprise points $(0,2)$ and $(1,2)$. This is exactly what it has been obtained.

Similarly, the dilation of the image is calculated as follows :

$$
\begin{aligned}
& \mu_{\mathrm{D}}(0,0)=\mu_{\mathrm{A} \oplus\left[\mathrm{B}_{1}, \mathrm{~B}_{2}, 1\right]}(0,0)=\max [0, \max [0.2+0.9-1,1+0.8-1]]=0.8 \\
& \mu_{\mathrm{D}}(0,1)=\max [0, \max [0.2+0.9-1,1+0.9-1,0.8+0.8-1]]=0.9 \\
& \cdot \\
& \cdot \\
& \mu_{\mathrm{D}}(5,2)=\max [0, \max [0.2+0.8-1,0.2+0.9-1,0.1+0.9-1]]=0.1
\end{aligned}
$$


Therefore, the dilated image is :

\begin{tabular}{|c|c|c|c|c|c|}
\hline$\sqrt{0.8}$ & 0.9 & 0.9 & 0.8 & 0.7 & 0.7 \\
\hline 0.7 & 0.8 & 0.8 & 0.8 & 0.7 & 0.6 \\
\hline 0.7 & 0.8 & 0.9 & 0.9 & 0.8 & 0.1 \\
\hline
\end{tabular}

As it can be seen, fuzzy soft dilation expands the image. In other words the dilated image includes the points of the original image and also points $(0,0)$, $(0,5),(1,0),(1,5)$, and $(2,0)$.

\section{Case $2: k=2$}

The erosion of the image is calculated as follows :

$\mu_{?}(0,0)=\mu_{\mathrm{AE}} \sum_{\left.\mathrm{B}_{1}, \mathrm{~B}_{2}, 2\right]}(0,0)=\min [1,2 \mathrm{nd}$ smallest $[0.3,0.3,1.1,1.1,1]]=0.3$

$\mu_{?}(0,1)=\min [1,2$ nd smallest $[0.4,1.1,1.1,0.9,0.9,0.9]]=0.9$

$\mu_{?}(5,2)=\min [1,2$ nd smallest $[0.4,0.2,0.2]]=0.2$

The eroded image for $k=2$ is :

\begin{tabular}{|c|c|c|c|c|c|}
\hline$\sqrt{0.3}$ & 0.9 & 0.8 & 0.8 & 0.4 & 0.4 \\
\hline 0.4 & 1.0 & 0.9 & 0.8 & 0.3 & 0.3 \\
\hline 0.2 & 0.4 & 0.3 & 0.3 & 0.2 & 0.2 \\
\hline
\end{tabular}

In this case the values of the eroded image at points $(0,1),(0,2),(0,3),(1$, $1),(1,2)$ and $(1,3)$ are higher than the rest values of the image. This is in agreement with the notion of fuzzy soft fitting. At these points the repeated $k$ times "high value" pixels, which are combined with the core of the structuring 
element, plus the pixels which are combined with the soft boundary of the structuring element, are greater than or equal to the $k \mathrm{Card}\left[\mathrm{B}_{1}\right]+\mathrm{Card}\left[\mathrm{B}_{2}\right]-$ $k+1$.

Similarly the dilation of the image is calculated :

$\mu_{\mathrm{D}}(0,0)=\mu_{\mathrm{A} \oplus\left[\mathrm{B}_{1}, \mathrm{~B}_{2}, 2\right]}(0,0)=\max [0,2$ nd $1 \arg \operatorname{est}[0.1,0.1,0.8]]=0.1$

$\mu_{\mathrm{D}}(0,1)=\max [0,2$ nd $1 \operatorname{argest}[0.1,0.1,0.9,0.9,0.6]]=0.9$

$\mu_{\mathrm{D}}(5,2)=\max [0,2 \mathrm{nd} 1 \arg \operatorname{est}[0.0,0.1,0.1,0.0,0.0]]=0.1$

Therefore, the dilated image for $k=2$ is :

\begin{tabular}{|c|c|c|c|c|c|}
\hline $\overrightarrow{\gamma 0.1}$ & 0.9 & 0.9 & 0.7 & 0.7 & 0.7 \\
\hline 0.2 & 0.8 & 0.8 & 0.8 & 0.7 & 0.6 \\
\hline 0.0 & 0.8 & 0.9 & 0.9 & 0.1 & 0.1 \\
\hline
\end{tabular}

Here again fuzzy soft dilation expands the image, but more 'softly', than when $k=1$. This means that certain points which were previously belonging $(k=1)$ to the image $((0,0),(1,0),(2,0)$ and $(2,4))$, now these belong $(k=2)$ to the background. The greater the $k$, the less the effect of the dilation.

Finally, fuzzy soft opening and closing are defined, as :

$\mu_{\mathrm{A} \circ\left[\mathrm{B}_{1}, \mathrm{~B}_{2}, k\right]}(x) \equiv \mu_{\left(\mathrm{A} \grave{\mathrm{E}}\left[\mathrm{B}_{1}, \mathrm{~B}_{2}, k\right]\right) \oplus\left[\mathrm{B}_{1}, \mathrm{~B}_{2}, k\right]}(x)$

and

$\mu_{\mathrm{A} \bullet\left[\mathrm{B}_{1}, \mathrm{~B}_{2}, k\right]}(x) \equiv \mu_{\left(\mathrm{A} \oplus\left[\mathrm{B}_{1}, \mathrm{~B}_{2}, k\right]\right)}{\grave{\mathrm{E}}\left[\mathrm{B}_{1}, \mathrm{~B}_{2}, k\right]}(x)$

respectively. 
Lets us consider Example 1. By thresholding image A and structuring element B (using a threshold equal to 0.5), the following binary image and binary structuring element are obtained :

\begin{tabular}{|c|c|c|c|c|c|}
\hline $\overrightarrow{60.0}$ & 1.0 & 1.0 & 1.0 & 1.0 & 0.0 \\
\hline 0.0 & 1.0 & 1.0 & 1.0 & 1.0 & 0.0 \\
\hline 0.0 & 1.0 & 1.0 & 0.0 & 0.0 & 0.0 \\
\hline
\end{tabular}

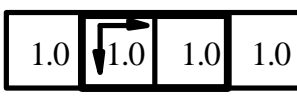

$\mathrm{B}$

A

By applying soft binary erosion and soft binary dilation to image A with structuring element $\mathrm{B}$ the following images are obtained for $k=1$ and $k=2$ :

$k=1$ :

\begin{tabular}{|c|c|c|c|c|c|}
\hline$\sqrt{0.0}$ & 0.0 & 1.0 & 0.0 & 0.0 & 0.0 \\
\hline 0.0 & 0.0 & 1.0 & 0.0 & 0.0 & 0.0 \\
\hline 0.0 & 0.0 & 0.0 & 0.0 & 0.0 & 0.0 \\
\hline
\end{tabular}

\begin{tabular}{|l|l|l|l|l|l|}
\hline$\sqrt{1.0}$ & 1.0 & 1.0 & 1.0 & 1.0 & 1.0 \\
\hline 1.0 & 1.0 & 1.0 & 1.0 & 1.0 & 1.0 \\
\hline 1.0 & 1.0 & 1.0 & 1.0 & 1.0 & 0.0 \\
\hline
\end{tabular}

$k=2$ :

\begin{tabular}{|c|c|c|c|c|c|}
\hline$\sqrt{0.0}$ & 1.0 & 1.0 & 1.0 & 0.0 & 0.0 \\
\hline 0.0 & 1.0 & 1.0 & 1.0 & 0.0 & 0.0 \\
\hline 0.0 & 0.0 & 0.0 & 0.0 & 0.0 & 0.0 \\
\hline
\end{tabular}

\begin{tabular}{|c|c|c|c|c|c|}
\hline$\vec{\gamma} 0.0$ & 1.0 & 1.0 & 1.0 & 1.0 & 1.0 \\
\hline 0.0 & 1.0 & 1.0 & 1.0 & 1.0 & 1.0 \\
\hline 0.0 & 1.0 & 1.0 & 1.0 & 0.0 & 0.0 \\
\hline
\end{tabular}

It is obvious that these results are identical to those of Example 1, when the same threshold value is used. This was expected, since binary soft morphology quantifies the soft fitting in a crisp way, whereas fuzzy soft erosion quantifies the soft fitting in a fuzzy way. The same results are obtained using a threshold equal to 0.55. However, when fuzzy soft morphology and thresholding with a threshold equal to 0.6 on the one hand and thresholding with the same threshold and soft morphology on the other 
hand are applied, different results will be obtained. This means that the operations, generally, do not commute.

\subsection{Algebraic properties in fuzzy soft mathematical morphology}

The following algebraic properties for fuzzy soft erosion and dilation, as well as for fuzzy soft opening and closing operations are studied :

\section{Duality Theorem}

Fuzzy soft erosion and dilation are dual operations i.e.:

$\left.\mu_{\mathrm{A}^{\mathrm{c}} \oplus\left[-\mathrm{B}_{1},-\mathrm{B}_{2}, k\right]}(x)=\mu_{(\mathrm{A}} \grave{\mathrm{E}}\left[\mathrm{B}_{1}, \mathrm{~B}_{2}, k\right]\right)^{\mathrm{c}}(x)$

Proof:

$$
\begin{aligned}
& \mu_{\left(\mathrm{A} \dot{\mathrm{E}}\left[\mathrm{B}_{1}, \mathrm{~B}_{2}, k\right]\right)^{\mathrm{C}}}(x)=1-\mu_{\mathrm{A}} \grave{\mathrm{E}}_{\left[\mathrm{B}_{1}, \mathrm{~B}_{2}, k\right]}(x) \\
& =1-\min \left[1 , k \text { th smallest } \operatorname { s e f } \left(\left\{k \diamond\left(\mu_{\substack{y \in B_{1} \\
z \in B_{2}}}(x+y)-\mu_{\mathrm{B}_{1}}(y)+1\right)\right\} \cup\right.\right. \\
& \left.\left.\left\{\mu_{\mathrm{A}}(x+z)-\mu_{\mathrm{B}_{2}}(z)+1\right\}\right)\right] \\
& =\max \left[1-1,1-\left[k \text { th } \operatorname { s m a l l } _ { \substack { y \in \mathrm { B } _ { 1 } \\
z \in \mathrm { B } _ { 2 } } } \operatorname { s e s t } \text { of } \left(\left\{k \diamond\left(\mu_{\mathrm{A}}(x+y)-\mu_{\mathrm{B}_{1}}(y)+1\right)\right\} \cup\right.\right.\right. \\
& \left.\left.\left.\left\{\mu_{\mathrm{A}}(x+z)-\mu_{\mathrm{B}_{2}}(z)+1\right\}\right)\right]\right]
\end{aligned}
$$




$$
\begin{aligned}
& =\max \left[0 , k \text { th } \underset { \substack { y \in \mathrm { B } _ { 1 } \\
z \in \mathrm { B } _ { 2 } } } { \operatorname { a r g } \operatorname { e s t } } \operatorname { o f } \left(\left\{k \diamond\left(1-\left(\mu_{\mathrm{A}}(x+y)-\mu_{\mathrm{B}_{1}}(y)+1\right)\right)\right\} \cup\right.\right. \\
& \left.\left.\left.\left\{1-\left(\mu_{\mathrm{A}}(x+z)-\mu_{\mathrm{B}_{2}}(z)+1\right)\right\}\right)\right]\right] \\
& =\max \left[0 , k \text { th } 1 \underset { \substack { y \in \mathrm { B } _ { 1 } \\
z \in \mathrm { B } _ { 2 } } } { \operatorname { a r g } \operatorname { e s t } } \operatorname { o f } \left(\left\{k \diamond\left(-\mu_{\mathrm{A}}(x+y)+\mu_{\mathrm{B}_{1}}(y)\right)\right\} \cup\right.\right. \\
& \left.\left.\left.\left\{-\mu_{\mathrm{A}}(x+z)+\mu_{\mathrm{B}_{2}}(z)\right\}\right)\right]\right] \\
& =\max \left[0 , k \text { th } \underset { \substack { y \in \mathrm { B } _ { 1 } \\
z \in \mathrm { B } _ { 2 } } } { \operatorname { a r g } \operatorname { e s t } } \operatorname { o f } \left(\left\{k \diamond\left(\mu_{\mathrm{A}^{\mathrm{c}}}(x+y)-1+\mu_{\mathrm{B}_{1}}(y)\right)\right\} \cup\right.\right. \\
& \left.\left.\left.\left\{\mu_{\mathrm{A}^{\mathrm{c}}}(x+z)-1+\mu_{\mathrm{B}_{2}}(z)\right\}\right)\right]\right] \\
& =\mu_{\mathrm{A} \oplus\left[-\mathrm{B}_{1},-\mathrm{B}_{2}, k\right]}(x)
\end{aligned}
$$

Eqn. (4) and identities [16] :

$k$ th largest of $(p, q)=-k$ th smallest of $(-p,-q)$ and

$k$ th largest of $(p, q)+r=k$ th 1 argest of $(p+r, q+r)$

have been used, to prove the duality theorem.

Opening and closing are also dual operations i.e.:

$$
\mu_{\left(\mathrm{A} \bullet\left[\mathrm{B}_{1}, \mathrm{~B}_{2}, k\right]\right)^{\mathrm{c}}}(x)=\mu_{\mathrm{A}^{\mathrm{c}} \circ\left[-\mathrm{B}_{1},-\mathrm{B}_{2}, k\right]}(x)
$$

Proof:

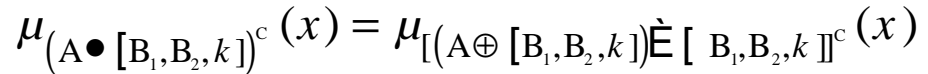

$$
\begin{aligned}
& =\mu_{\left(\mathrm{A} \oplus\left[\mathrm{B}_{1}, \mathrm{~B}_{2}, k\right]\right)^{\mathrm{C}} \oplus\left[-\mathrm{B}_{1},-\mathrm{B}_{2}, k\right]}(x)
\end{aligned}
$$

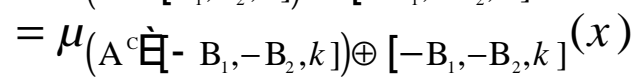

$$
\begin{aligned}
& =\mu_{\mathrm{A}^{\mathrm{c}} \circ\left[-\mathrm{B}_{1},-\mathrm{B}_{2}, k\right]}(x)
\end{aligned}
$$

\section{Translation Invariance}

Fuzzy soft erosion and dilation are translation invariant, i.e. :

$$
\mu_{(\mathrm{A})_{\mathrm{u}} \mathrm{È}\left[\mathrm{B}_{1}, \mathrm{~B}_{2}, k\right]}(x)=\left(\mu_{\mathrm{AE}\left[\mathrm{B}_{1}, \mathrm{~B}_{2}, k\right]}(x)\right)_{\mathrm{u}}
$$


where $\mathrm{u} \in \mathrm{Z}^{2}$.

Proof:

$$
\begin{aligned}
& \left(\mu_{\mathrm{A} \dot{\mathrm{E}}\left[\mathrm{B}_{1}, \mathrm{~B}_{2}, k\right]}(x)\right)_{\mathrm{u}}=\mu_{\mathrm{A} \grave{\mathrm{E}}\left[\mathrm{B}_{1}, \mathrm{~B}_{2}, k\right]}(x+\mathrm{u}) \\
& =\min \left[1 , k \text { th smallest of } \left(\left\{k \diamond\left(\mu_{\substack{y \in B_{1} \\
z \in B_{2}}}(x+\mathrm{u}+y)-\mu_{\mathrm{B}_{1}}(y)+1\right)\right\} \cup\right.\right. \\
& \left.\left.\left\{\mu_{\mathrm{A}}(x+\mathrm{u}+z)-\mu_{\mathrm{B}_{2}}(z)+1\right\}\right)\right]
\end{aligned}
$$

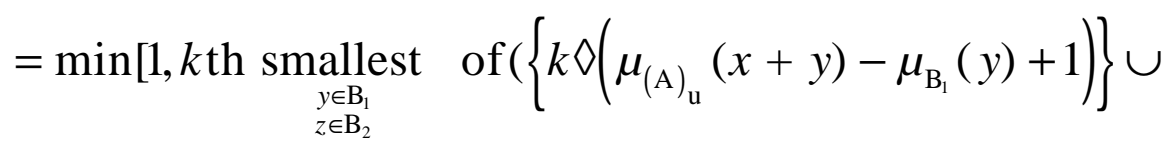

$$
\begin{aligned}
& \left.\left.\left\{\mu_{(\mathrm{A})}(x+z)-\mu_{\mathrm{B}_{2}}(z)+1\right\}\right)\right]
\end{aligned}
$$

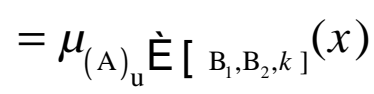

Similarly, or by the duality theorem (eqn. (25)) it can be proven that fuzzy soft dilation is also invariant under translation.

\section{Increasing}

Both fuzzy soft erosion and dilation are increasing operations, i.e. :

$\mu_{?}<\mu_{?^{\prime}} \Rightarrow\left\{\begin{array}{l}\mu_{\mathrm{A} \grave{\mathrm{E}}\left[\mathrm{B}_{1}, \mathrm{~B}_{2}, k\right]}(x)<\mu_{\mathrm{A}^{\prime} \grave{\mathrm{E}}\left[\mathrm{B}_{1}, \mathrm{~B}_{2}, k\right]}(x) \\ \mu_{\mathrm{A} \oplus\left[\mathrm{B}_{1}, \mathrm{~B}_{2}, k\right]}(x)<\mu_{\mathrm{A}^{\prime} \oplus\left[\mathrm{B}_{1}, \mathrm{~B}_{2}, k\right]}(x)\end{array}\right.$

where $\mathrm{A}$ and $\mathrm{A}$ ?, are two images with membership functions $\mu_{2}$ and $\mu_{\mathrm{A}}$ ? respectively and $\mu_{2}<\mu_{\mathrm{A} \text { ? }}$ in the whole $\mathrm{Z}^{2}$ grid.

Proof: 


$$
\begin{aligned}
& \mu_{?}<\mu_{?,} \Rightarrow\left\{\begin{array}{l}
\mu_{?}(x+y)<\mu_{?},(x+y) \\
\mu_{?}(x+z)<\mu_{?}(x+z)
\end{array}\right. \\
& \Rightarrow\left\{\begin{array}{l}
\mu_{?}(x+y)-\mu_{\mathrm{B}_{1}}(y)+1<\mu_{?}(x+y)-\mu_{\mathrm{B}_{1}}(y)+1 \\
\mu_{?}(x+z)-\mu_{\mathrm{B}_{2}}(z)+1<\mu_{?} \cdot(x+z)-\mu_{\mathrm{B}_{2}}(z)+1
\end{array}\right. \\
& \Rightarrow \min \left[1 , k \text { th } \operatorname { s m a l l e s t } _ { \substack { y \in \mathrm { B } _ { 1 } \\
z \in \mathrm { B } _ { 2 } } } \text { of } \left(\left\{k \diamond\left(\mu_{\mathrm{A}}(x+y)-\mu_{\mathrm{B}_{1}}(y)+1\right)\right\} \cup\right.\right. \\
& \left.\left.\left\{\mu_{\mathrm{A}}(x+z)-\mu_{\mathrm{B}_{2}}(z)+1\right\}\right)\right] \\
& <\min \left[1 , k \text { th } \operatorname { s m a l l e s } _ { \substack { y \in \mathrm { B } _ { 1 } \\
z \in \mathrm { B } _ { 2 } } } \operatorname { s i n } \left(\left\{k \diamond\left(\mu_{\mathrm{A}^{\prime}}(x+y)-\mu_{\mathrm{B}_{1}}(y)+1\right)\right\} \cup\right.\right. \\
& \left.\left.\left\{\mu_{\mathrm{A}^{\prime}}(x+z)-\mu_{\mathrm{B}_{2}}(z)+1\right\}\right)\right] \\
& \Rightarrow \mu_{\mathrm{A} \grave{\mathrm{E}}\left[\mathrm{B}_{1}, \mathrm{~B}_{2}, k\right]}(x)<\mu_{\mathrm{A}}{\grave{\mathrm{E}}\left[\mathrm{B}_{1}, \mathrm{~B}_{2}, k\right]}(x)
\end{aligned}
$$

Similarly, or by the duality theorem it is proven that fuzzy soft dilation is also an increasing operation.

\section{Distributivity}

Fuzzy soft erosion is not distributive over intersection, as it is in standard morphology; i.e. in general :

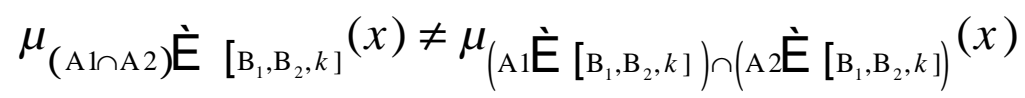

An illustrative example follows :

Example 2 : Consider image A and structuring element B. Suppose that image $\mathrm{A}$ is the intersection of two images $\mathrm{A} 1$ and $\mathrm{A} 2$. 


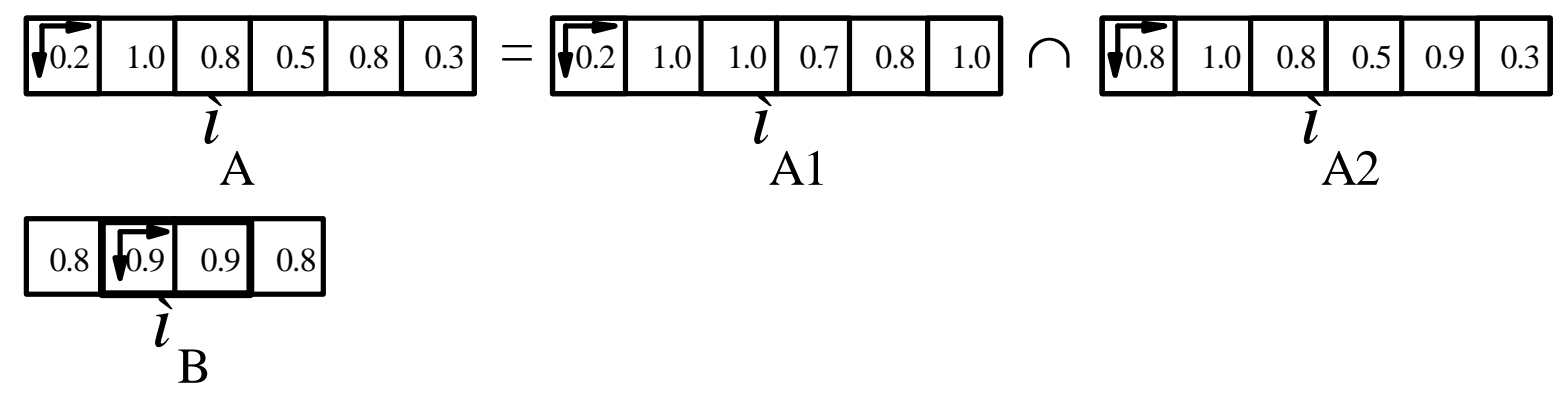

The fuzzy soft erosion for $k=2$ of A, A1, A2 and the intersection of the eroded A1 and the eroded A2 are, respectively:
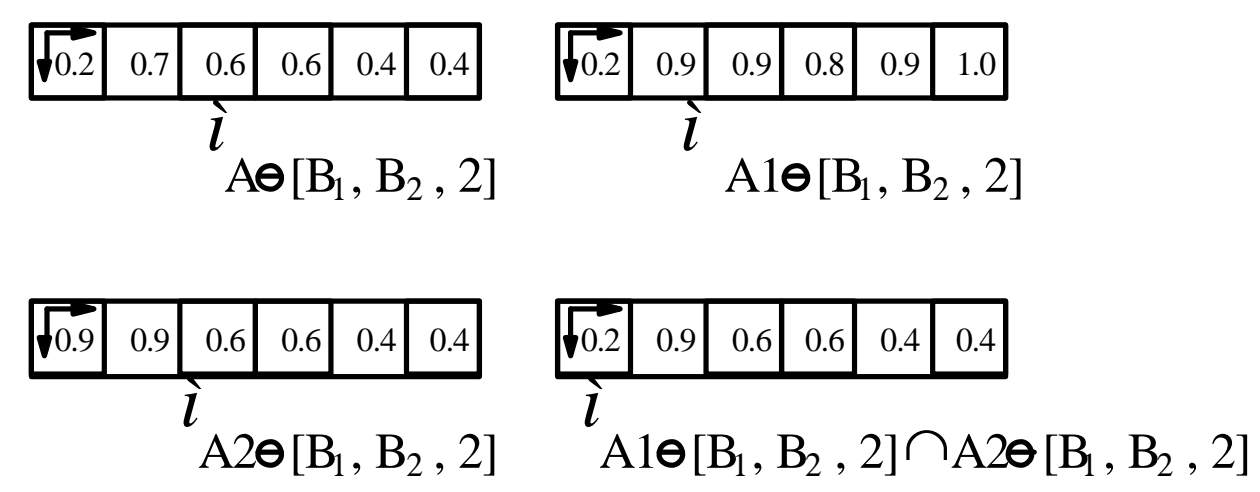

From the above example it is clear that $\mu_{(\mathrm{A} 1 \cap \mathrm{A} 2)} \mathrm{E}_{\left[\mathrm{B}_{1}, \mathrm{~B}_{2}, k\right]}(x) \neq$ $\left.\neq \mu_{(\mathrm{A} 1 \mathrm{E}}\left[\mathrm{B}_{1}, \mathrm{~B}_{2}, k\right]\right) \cap\left(\mathrm{A}_{2} \grave{\mathrm{E}}_{\left.\left[\mathrm{B}_{1}, \mathrm{~B}_{2}, k\right]\right)}(x)\right.$, and thus fuzzy soft erosion generally does not distribute over intersection.

Similarly, or by the duality theorem it can be proven that fuzzy soft dilation does in general not distribute over union :

$\mu_{(\mathrm{A} 1 \cup \mathrm{A} 2) \oplus\left[\mathrm{B}_{1}, \mathrm{~B}_{2}, k\right]}(x) \neq \mu_{\left(\mathrm{A} 1 \oplus\left[\mathrm{B}_{1}, \mathrm{~B}_{2}, k\right]\right) \cup\left(\mathrm{A} 2 \oplus\left[\mathrm{B}_{1}, \mathrm{~B}_{2}, k\right]\right)}(x)$

Anti-extensivity - Extensivity

Fuzzy soft opening is not anti-extensive. If it were anti-extensive, then : $\mu_{? \circ\left[?_{B}, ?_{2}, k\right]}(x) \leq \mu_{?}(x), \forall x \in Z^{2}$. However, in the following example it is shown that $\exists x \in \mathrm{Z}^{2}$, so that : $\mu_{\mathrm{A}_{\mathrm{A}\left[\mathrm{B}_{1}, \mathrm{~B}_{2}, k\right]}}(x)>\mu_{\mathrm{A}}(x)$. Similarly, it is shown that, in general, fuzzy soft closing is not extensive too : $\exists x \in \mathrm{Z}^{2}$, so that : $\mu_{\mathrm{A} \bullet\left[\mathrm{B}_{1}, \mathrm{~B}_{2}, k\right]}(x)<\mu_{\mathrm{A}}(x)$. 
Example 3 : Consider the image A and the structuring element $\mathrm{B}$, for $k=2$.

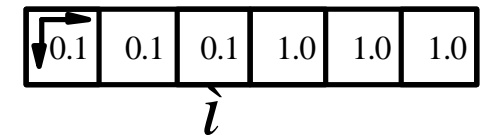

A

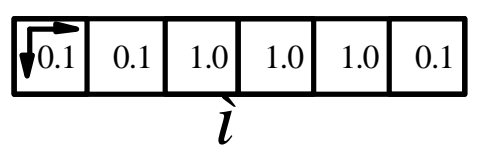

$\mathrm{A} \circ \mathrm{B}$

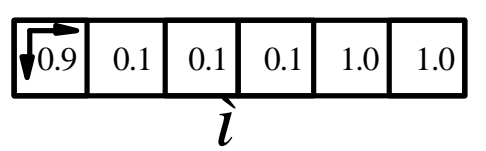

$\mathrm{A} \bullet \mathrm{B}$

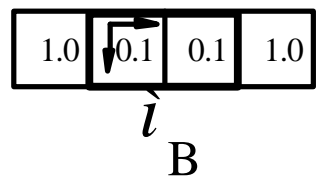

B

In the above example $\mu_{\mathrm{A} \circ\left[\mathrm{B}_{1}, \mathrm{~B}_{2}, k\right]}(0,2)=1.0>\mu_{\mathrm{A}}(0,2)=0.1$, which means that fuzzy soft opening is not anti-extensive. Also, $\mu_{\mathrm{A} \bullet\left[\mathrm{B}_{1}, \mathrm{~B}_{2}, k\right]}(0,3)=0.1<\mu_{\mathrm{A}}(0,3)=1.0$, which means that fuzzy soft closing is not extensive too.

\section{Idempotency}

Fuzzy soft opening and closing have been defined as fuzzy soft erosion followed by fuzzy soft dilation and fuzzy soft dilation followed by fuzzy soft erosion, respectively. However, in algebra an application is said to be an opening if it is anti-extensive, increasing and idempotent [2]. It is straightforward that fuzzy soft opening is increasing, since both fuzzy soft erosion and dilation are increasing. It has been shown that fuzzy soft opening is not anti-extensive (Example 3). Also, in general, fuzzy soft opening is not idempotent :

$\mu_{\mathrm{A} \circ\left[\mathrm{B}_{1}, \mathrm{~B}_{2}, k\right]}(x) \neq \mu_{\left(\mathrm{A} \circ\left[\mathrm{B}_{1}, \mathrm{~B}_{2}, k\right]\right) \circ\left[\mathrm{B}_{1}, \mathrm{~B}_{2}, k\right]}(x)$

This is illustrated by the following example : 
Example 4 : Consider the image A and the structuring element $\mathrm{B}$, for $k=1$.

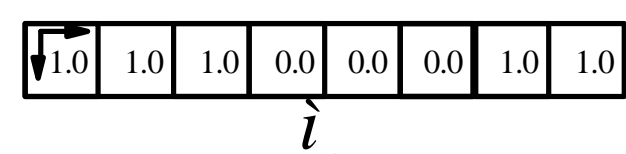

A

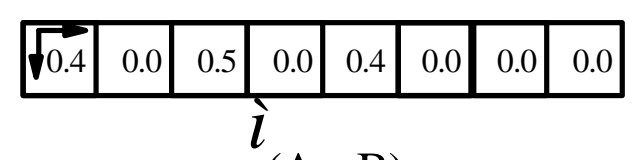

$(\mathrm{A} \circ \mathrm{B})$

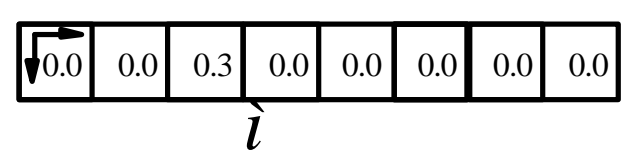

$(\mathrm{A} \circ \mathrm{B}) \circ \mathrm{B}$

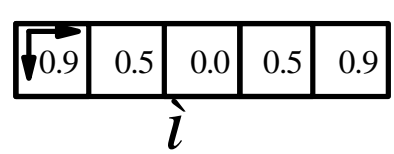

B

From the above example it is obvious that fuzzy soft opening is not idempotent. By duality theorem (eqn. (26)) it can be proven that, in general, fuzzy soft closing is not idempotent too :

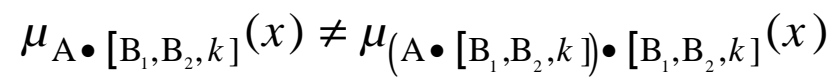

\section{Experimental Results}

Illustration of the basic fuzzy soft morphological operations defined in this paper are given through 1-dimensional (1-d) and 2-dimensional (2-d) images. Figure 1 depicts fuzzy soft morphological erosion and dilation in 1-d space. More specifically, Figure 1a shows the initial 1-d image and Figure $1 \mathrm{~b}$ shows the structuring element. The core of the structuring element is the shaded area and the rest area of the structuring element is the soft boundary. Figures $1 \mathrm{c}$ and $1 \mathrm{~d}$ are the images for $k=1$ of fuzzy soft erosion and fuzzy soft dilation, respectively. Figures $1 \mathrm{e}$ and $1 \mathrm{f}$ are the images for $k=2$ of fuzzy soft erosion and fuzzy soft dilation, respectively. In the latter four 
Figures the original image is represented by a dotted line and the results by a continuous line. By comparing Figure 1c with Figure 1e and Figure 1d with Figure 1f it becomes clear that the action of the structuring element is more effective when $k=1$, i.e. the results of both fuzzy soft erosion and dilation are more visible in case of $k=1$, than in case of $k=2$.

Figure 2 shows the result of fuzzy soft morphological erosion and dilation in a 2-d image. Figure $3 a$ shows the initial image. Figure $2 b$ shows the structuring element. The core of the structuring element is separated from the soft boundary by the bold line. Experiments have been performed using a commercial frame grabber. The image in Figure $2 b$ has been considered as an array of fuzzy singletons [14]. The results of fuzzy soft erosion $(k=1)$ after the first and the second interaction are presented in Figures $2 \mathrm{c}$ and $2 \mathrm{~d}$, respectively. The white area is reduced after each interaction. The white area of the eroded image (Figure 2c) is the area of the initial image, where the structuring element fits better. Similarly, in Figures $2 \mathrm{e}$ and $2 \mathrm{f}$ are presented the results of fuzzy soft erosion $(k=3)$ after the first and the second interaction. Comparing Figures $2 \mathrm{c}$ and $2 \mathrm{e}$ it is made clear that the greater the $k$ the less visible the results of fuzzy soft erosion. Figures $2 \mathrm{~g}$ and $2 \mathrm{~h}$ present the results of fuzzy soft dilation $(k=1)$ after the first and the second interaction, respectively. In the case of fuzzy soft dilation the white area increases. Similarly in Figures $2 \mathrm{i}$ and $2 \mathrm{j}$ are presented the results of fuzzy soft dilation $(k=3)$ after the first and the second interaction. Again the greater the $k$ the less visible the results of fuzzy soft dilation.

\section{Conclusions}

A new approach to soft morphology has been presented in this paper. The proposed approach is based on fuzzy set theory. The definitions for the basic fuzzy soft morphological operations have been extracted and their 
algebraic properties have been studied. Fuzzy soft morphological operations inherit properties and restrictions of both soft morphology and fuzzy morphology. More specifically, it has been shown that fuzzy soft morphological operations are dual, translation invariant and increasing, whilst they do not distribute over basic set operations, such as intersection and union and they are not extensive, anti-extensive and idempotent. The definitions and the algebraic properties have been illustrated through examples and experimental results. 


\section{REFERENCES}

1 MATHERON, G. : 'Random sets and integral geometry' (Wiley, New York, 1975).

2 SERRA, J. : 'Image analysis and mathematical morphology : Vol.I' (Academic Press, London, 1982).

3 SERRA, J. : 'Introduction to mathematical morphology', Comp. Vision Graph. Imag. Proc., 1986, 35, (3), pp. 283-305.

4 STERNBERG, R. : 'Grayscale morphology', Computer Vision, Graphics and Image Processing, 1986, 35, (3), pp. 333-355.

5 HARALICK, R. M., STERNBERG, R., and ZHUANG, X. : 'Image analysis using mathematical morphology', IEEE Trans. Pattern Analysis and Machine Intelligence, 1987, PAMI-9, (4), pp. 532-550.

6 GONZALEZ, R. C. and WOODS, R. E.: 'Digital image processing' (Addison-Wesley, New York, 1992).

7 SHINHA, D., and DOUGHERTY, E. R. : 'Fuzzy mathematical morphology', Journal Visual Commun. Imag. Repres., 1992, 3, (3), pp. 286-302.

8 BLOCH, I., and MAITRE, H. : 'Fuzzy mathematical morphologies: a comparative study', Pattern Recognition, 1995, 28, (9), pp. 1341-1387.

9 KOSKINEN, L., ASTOLA, J., and NEUVO, Y. : 'Soft morphological filters', Proc. SPIE Symp. Image Algebra and Morphological Image Proc., 1991, 1568, pp. 262-270.

10 KUOSMANEN, P., and ASTOLA, J. : 'Soft morphological filtering', Journal Mathematical Imag. Vision, 1995, 5, (3), pp.231-262.

11 PU, C. C. and SHIH, F. Y.: 'Threshold decomposition of grey-scale soft morphology into binary soft morphology', Graphical Models and Image Processing, 1995, 57, pp. 522-526. 
12 SHIH, F. Y., and PU, C. C. : 'Analysis of the properties of soft morphological filtering using threshold decomposition', IEEE Trans. Signal Proc., 1995, 43, (2), pp.539-544.

13 ZADEH, L. A. : 'Fuzzy sets', Inform. Control, 1965, 8, pp.338-353.

14 GOETCHARIAN, V. : 'From binary to grey tone image processing using fuzzy logic concepts', Pattern Recognition, 1980, 12, (1), pp. 715.

15 BEZDEK, J. C. and PAL, S. K., (editors) : 'Fuzzy models for pattern recognition', (IEEE Press, New York, 1992).

16 DAVID, H. A. : 'Order statistics', (Wiley, New York, 1981) 2nd edn. 


\section{FIGURE CAPTIONS}

Figure 1 : (a) Initial 1-d fuzzy set, (b) structuring element, (c) fuzzy soft erosion $(k=1)$, (d) fuzzy soft dilation $(k=1)$, (e) fuzzy soft erosion $(k=2)$ and (f) fuzzy soft dilation $(k=2)$.

Figure 2 : (a) The initial image, (b) structuring element, (c) fuzzy soft erosion ( $k=1)$ after the first interaction, (d) fuzzy soft erosion $(k=1)$ after the second interaction, (e) fuzzy soft erosion $(k=3)$ after the first interaction, (f) fuzzy soft erosion $(k=3)$ after the second interaction, (g) fuzzy soft dilation $(k=1)$ after the first interaction, (h) fuzzy soft dilation $(k=1)$ after the second interaction, (i) fuzzy soft dilation ( $k=3$ ) after the first interaction and (j) fuzzy soft dilation $(k=3)$ after the second interaction. 


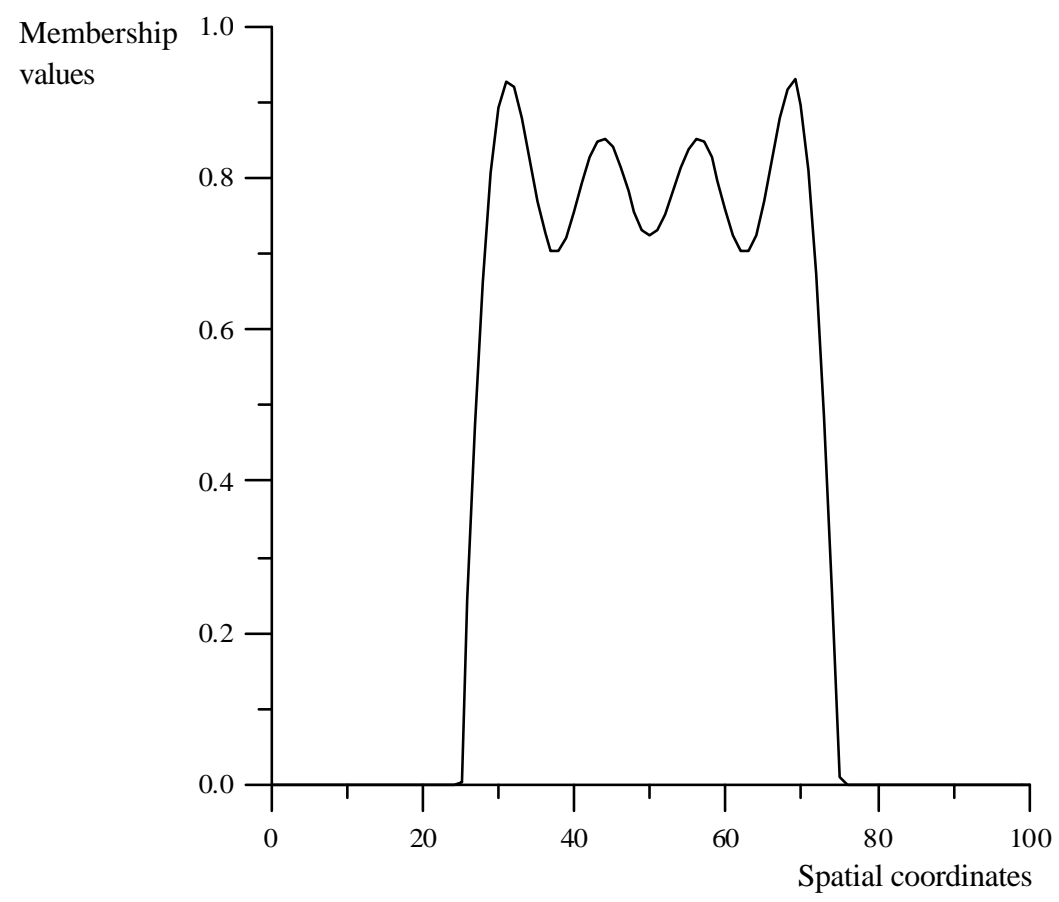

Figure 1a

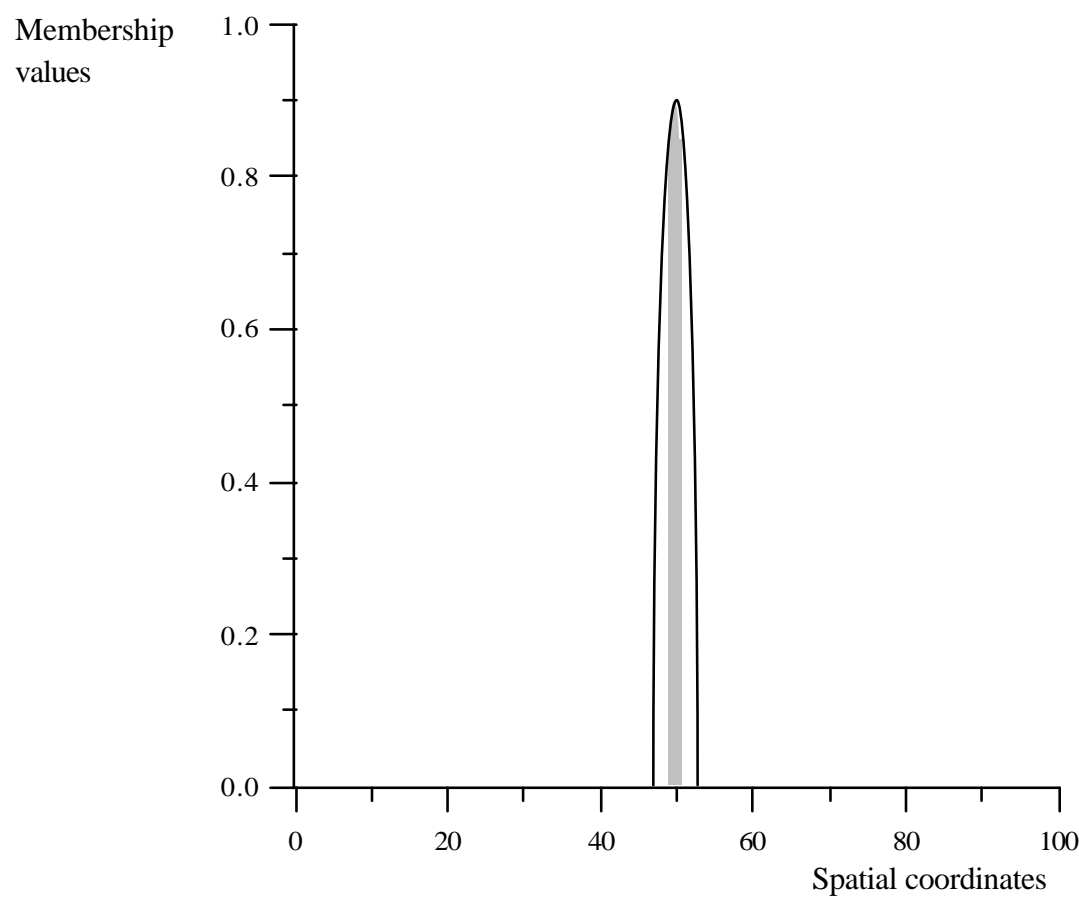

Figure 1b 


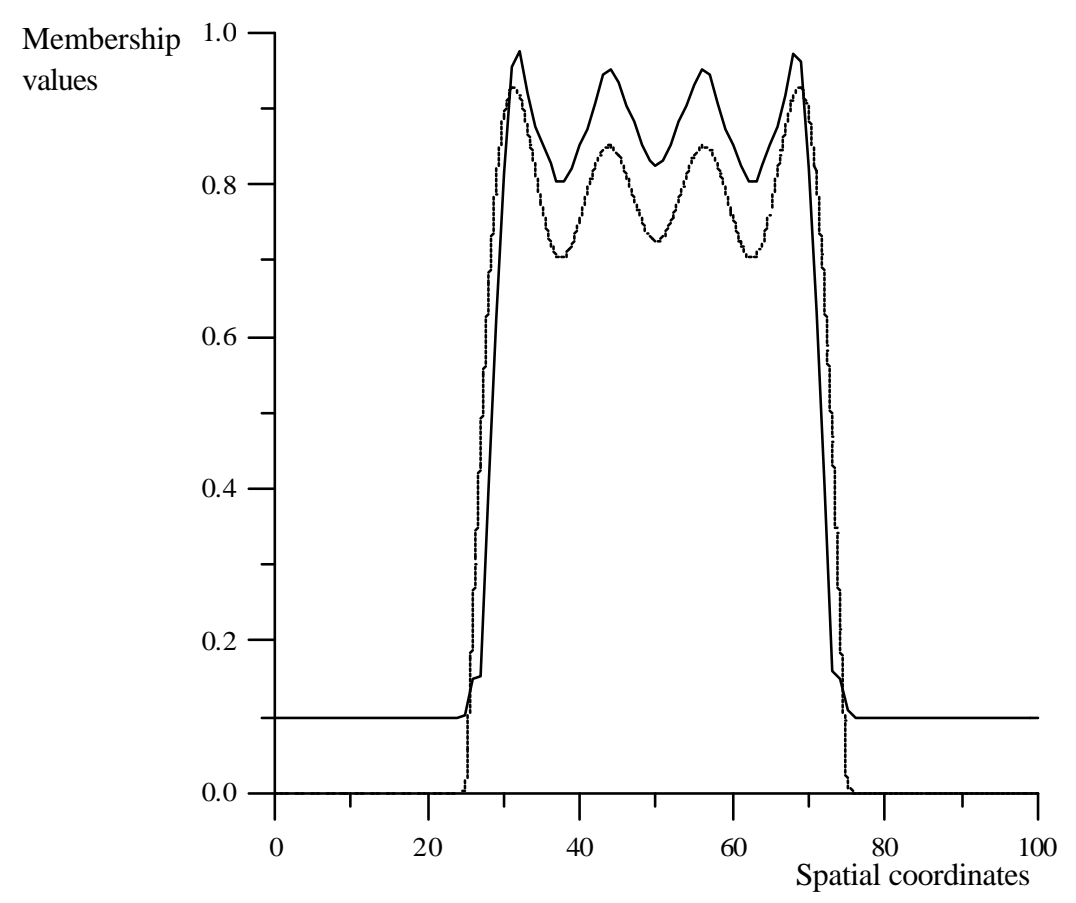

Figure 1c

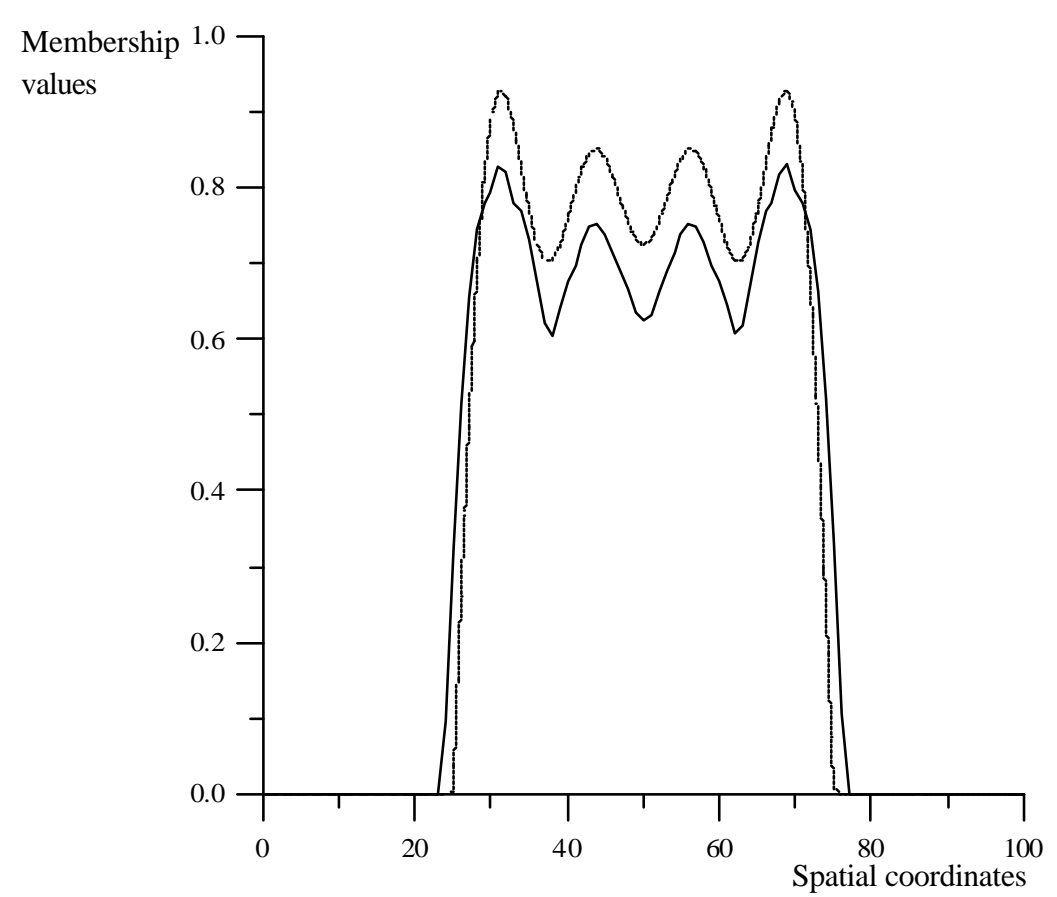

Figure 1d 


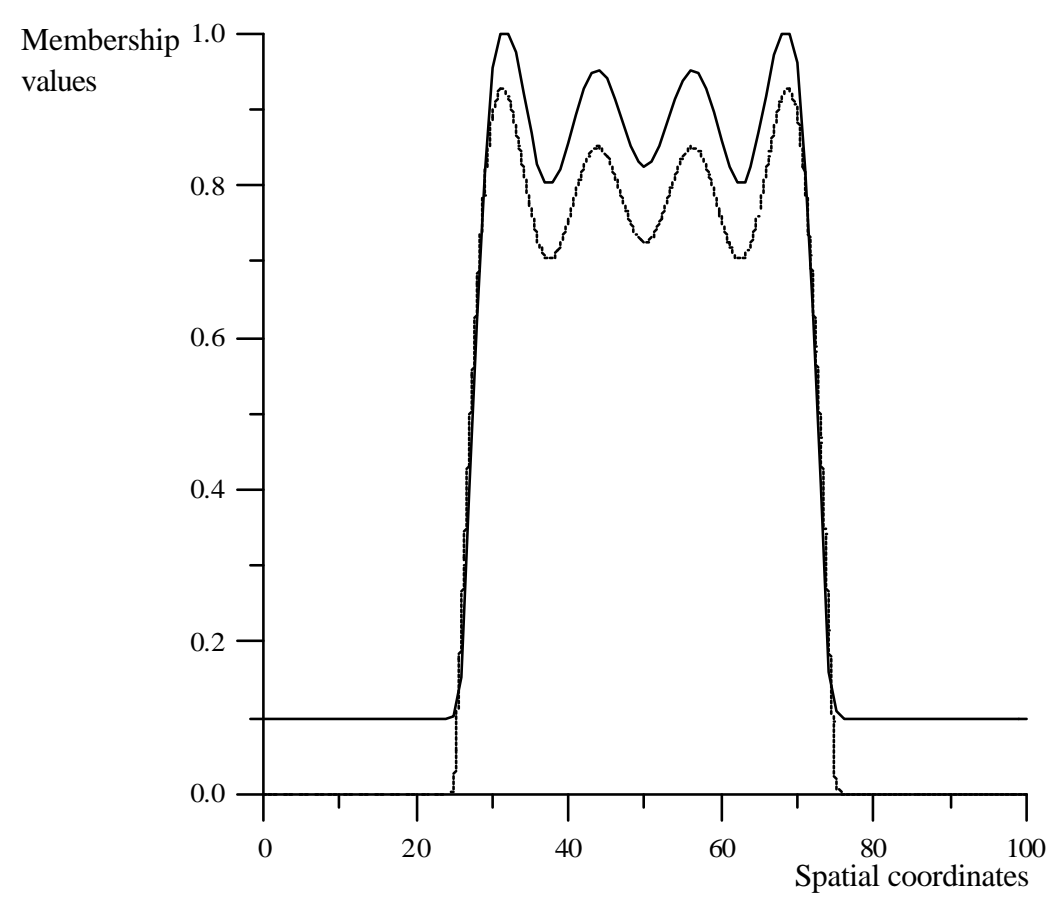

Figure 1e

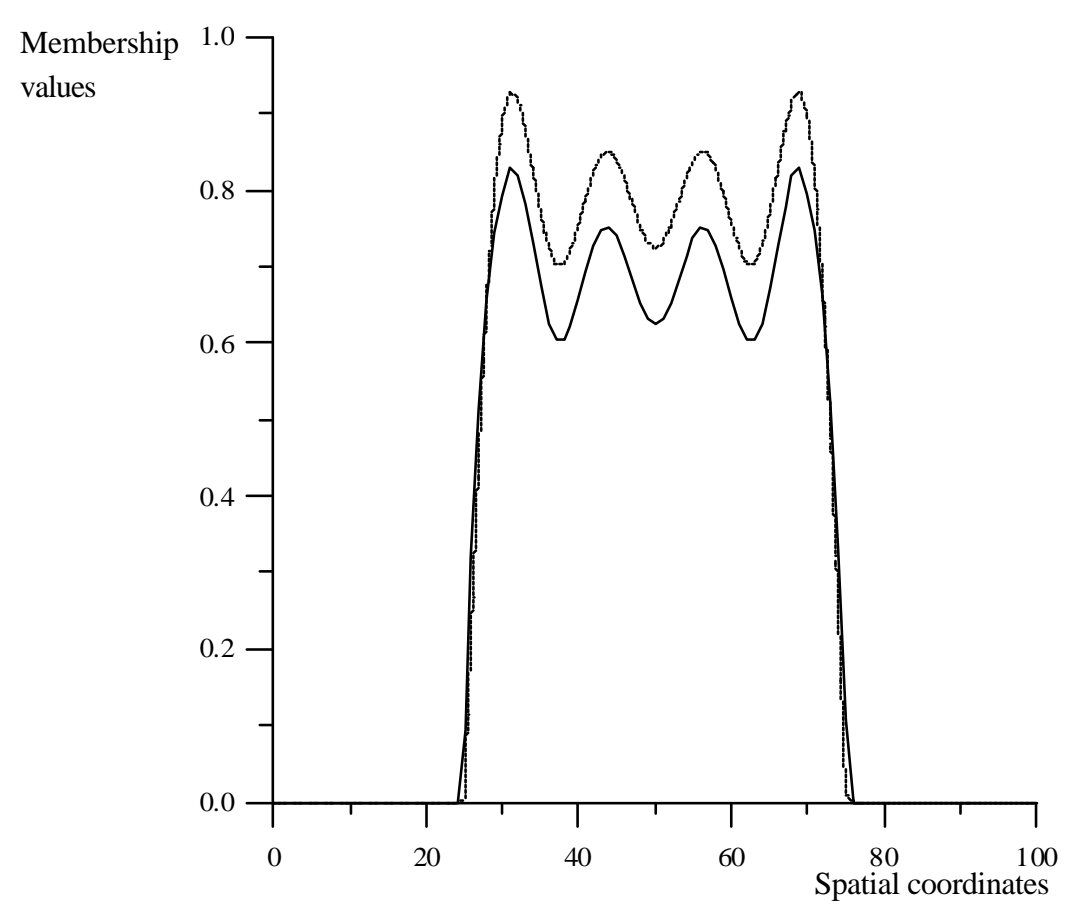

Figure 1f 


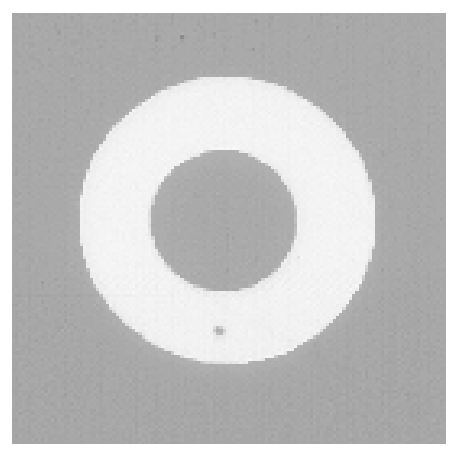

Figure 2a

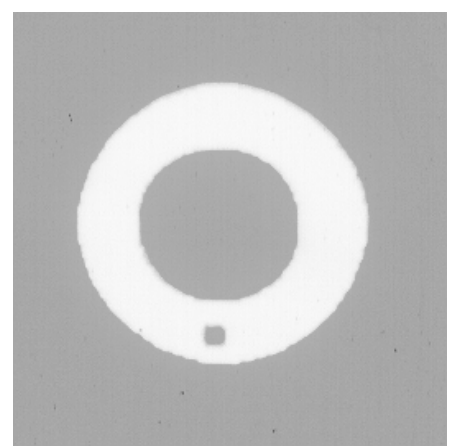

Figure 2d

\begin{tabular}{|l|l|l|l|l|}
\hline 1 & 1 & 1 & 1 & 1 \\
\hline 1 & 1 & 1 & 1 & 1 \\
\hline 1 & 1 & 1 & 1 & 1 \\
\hline 1 & 1 & 1 & 1 & 1 \\
\hline 1 & 1 & 1 & 1 & 1 \\
\hline
\end{tabular}

Figure 2b

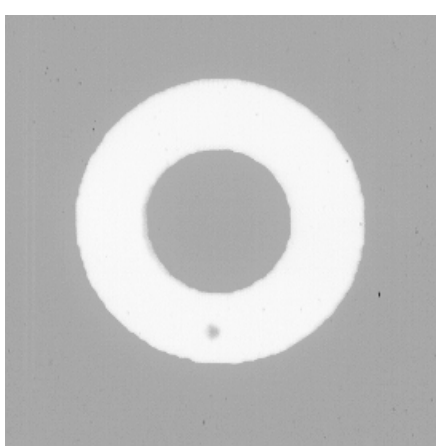

Figure 2e

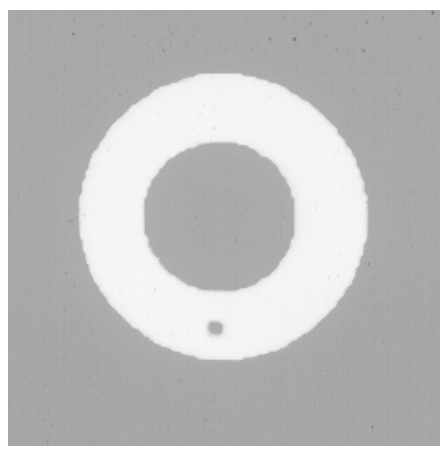

Figure 2c

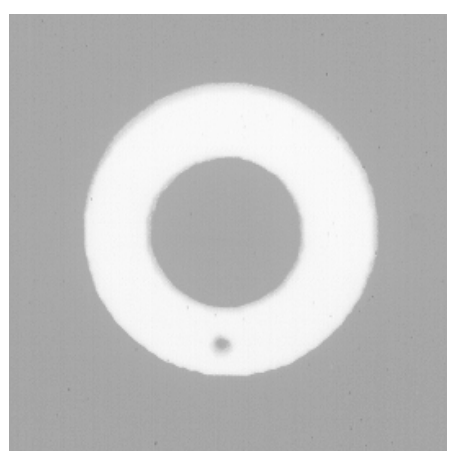

Figure 2f 


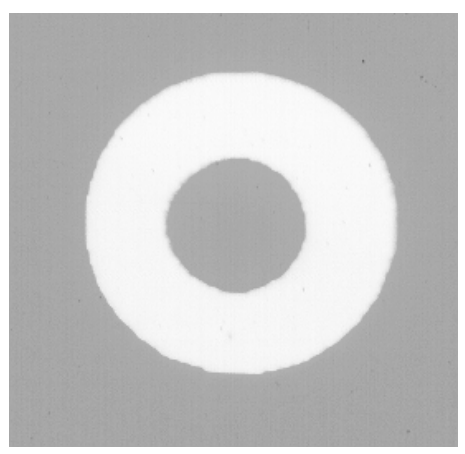

Figure 2g

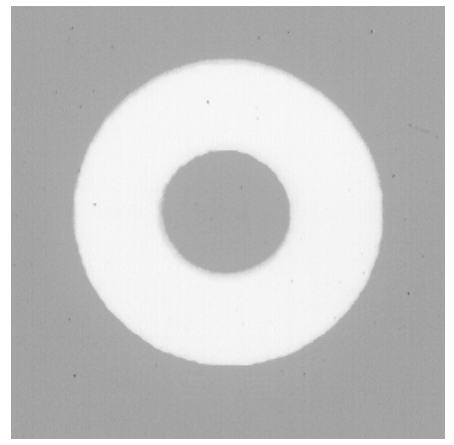

Figure 2j

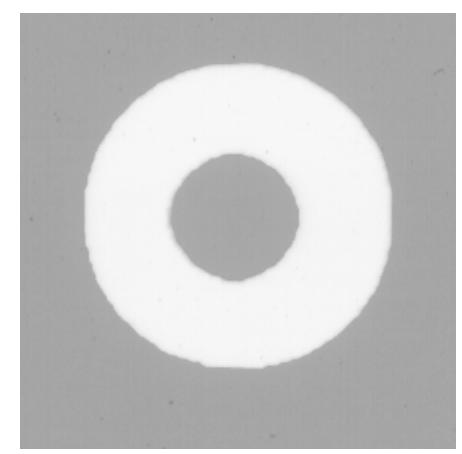

Figure 2h

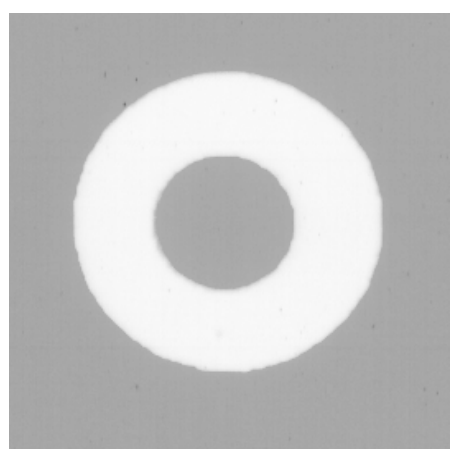

Figure 2i 